\title{
La persiana enrollable. Revisión del sistema constructivo y sus requisitos medioambientales
}

\section{The roller shutter. Review of the construction system and its environmental requirements}

$\underline{\text { N. Martí }}{ }^{(*)}$, R. Araujo ${ }^{(* *)}$

\section{RESUMEN}

El empobrecimiento de los filtros del hueco hace que su eficiencia medioambiental, integración en el sistema constructivo y cualidades compositivas y espaciales se vean drásticamente reducidas. La revisión de la persiana enrollable desde su evolución histórica como elemento fundamental de la transformación del hueco permite devolver al cerramiento y al hueco esa complejidad perdida y acercarnos a la necesaria tipificación de nuestras soluciones. La investigación de la persiana enrollable parte de las primeras patentes inglesas y francesas hasta llegar a España por medio de los Herederos de Ramón Múgica, en San Sebastián y Casas\&Bardes, en Barcelona, con múltiples soluciones constructivas integradas en los huecos. Su concepción a principios del s. xIx difiere de la actual tanto a nivel de acondicionamiento climático como constructivo y permite valorar, a través del análisis de algunos ejemplos, el cumplimiento de sus prestaciones e integración en el hueco y discernir qué soluciones emergentes son las más óptimas..

Palabras clave: Filtros del hueco; persiana enrollable; Gaudí y Herederos Múgica.

\section{ABSTRACT}

The impoverishment of the filters on the windows has drastically reduced their energy efficiency abilities and spatial qualities and the insertion into the construction system has worsened. The review of the roller shutter, from its historical development as an essential element of the evolution of the opening, allows us to rethink these lost complexities and to understand the categorization of our solutions. This research into the roller shutter starts from its first English and French patents, to arriving in Spain through Ramón Múgica's Inheritors in San Sebastián, and Casas\&Bardes in Barcelona with multiple construction solutions integrated into the holes. Their conception at the beginning of the 19th-century differed from the current one both climate and construction requirements and that allows us to analyze, using examples, compliance with their needs and insertion into the opening and to discern what emerging solutions are the most optimal.

Keywords: Opening filters; revolving shutter; Gaudí and Múgica’s Inheritors.

(*) ETSALS - Universitat Ramón Llull, Barcelona (España).

(**) ETSAM - Universidad Politécnica de Madrid (España).

Persona de contacto/Corresponding author: nmarti@salleurl.edu (N. Martí)

Cómo citar este artículo/Citation: Martí, N., Araujo, R. (2015). La persiana enrollable. Revisión del sistema constructivo y sus requisitos medioambientales. Informes de la Construcción, 67(540): e113, doi: http://dx.doi.org/10.3989/ic.14.069.

Licencia / License: Salvo indicación contraria, todos los contenidos de la edición electrónica de Informes de la Construcción se distribuyen bajo una licencia de uso y distribución Creative Commons Reconocimiento no Comercial 3.o. España (cc-by-nc). 


\section{INTRODUCCIÓN}

El hueco es un elemento complejo, que ha de ser capaz de integrar múltiples exigencias de diseño -desde su integración coherente en el sistema constructivo global a la resolución de múltiples detalles- y debe aportar una concepción convincente de control del ambiente: control solar térmico y lumínico, control visual, ventilación, aislar térmica y acústicamente, seguridad, etc. Y todo esto debe hacerlo de manera flexible, de modo que el sistema logre un alto grado de adaptación a condiciones cambiantes y cumpla con las exigencias medioambientales.

En la arquitectura decimonónica se desarrolló un tipo de hueco que respondía a todas estas características de modo más que convincente. Es el hueco balconero, característico de la ciudad del Ensanche, un diseño tan eficaz que se convierte en un elemento totalmente estandarizado que rara vez será desmentido y cuyo éxito se debe a las múltiples soluciones que va incorporando, desde un ritmo y tamaño óptimo para el vano hasta la definición de las escuadrías de la ventana a la francesa, incorporación de jambas y molduras con diferentes misiones, etc.

En este diseño eran fundamentales las persianas, ventanas, contraventanas y cortinas o visillos, insertados independientemente o bien mediante un marco telar en el haz interior de la fachada, cumpliendo cada uno con funciones específicas (Figura 1).

Las persianas o bien de cuerda o librillo desempeñaban principalmente la función de protección-control solar. Las prime- ras de uso más doméstico y de coste más económico, gracias a su faldón formado por tablillas de madera conectadas por ganchos metálicos, controlaban la radiación solar directa y permitían su proyección creando un espacio intermedio en sombra que además facilitaba la ventilación del interior. Las persianas de librillo, más nobles, gracias al pliegue vertical de las hojas y la orientación de las lamas en sentido horizontal; permitían controlar afinadamente la radiación en la doble orientación, además de permitir regular la iluminación, mejorar el comportamiento térmico y acústico o aportar seguridad.

Las ventanas desempeñaban la función de cerramiento, transparente. La fragmentación de la carpintería en su practicabilidad facilitaba la relación entre el ambiente interior y exterior. Las contraventanas favorecerían la oscuridad contribuyendo a la resistencia térmica y las cortinas blancas como elemento intimista conseguían una reflexión solar del orden del $50 \%$ (1) (2).

La arquitectura moderna, que nació finalmente asociada a un sistema constructivo absolutamente nuevo, abandonó completamente el hueco tradicional. En sus primeros años el control ambiental -que había sido determinante en las arquitecturas precedentes- fue prácticamente olvidado, apoyándose en la nueva confianza en la mecanización y la producción de energía sin límites, y como resultado de este proceso no sólo estamos hoy bien lejos de poder ofrecer una solución tan espléndida como el hueco decimonónico, sino que hemos asumido diseños y sistemas absolutamente ineficientes. En la actualidad todo aquel equipo de filtros de la ventana o bien ha desaparecido en favor de los vidrios especializados o se ha reducido en la mayoría de los casos a la persiana y más

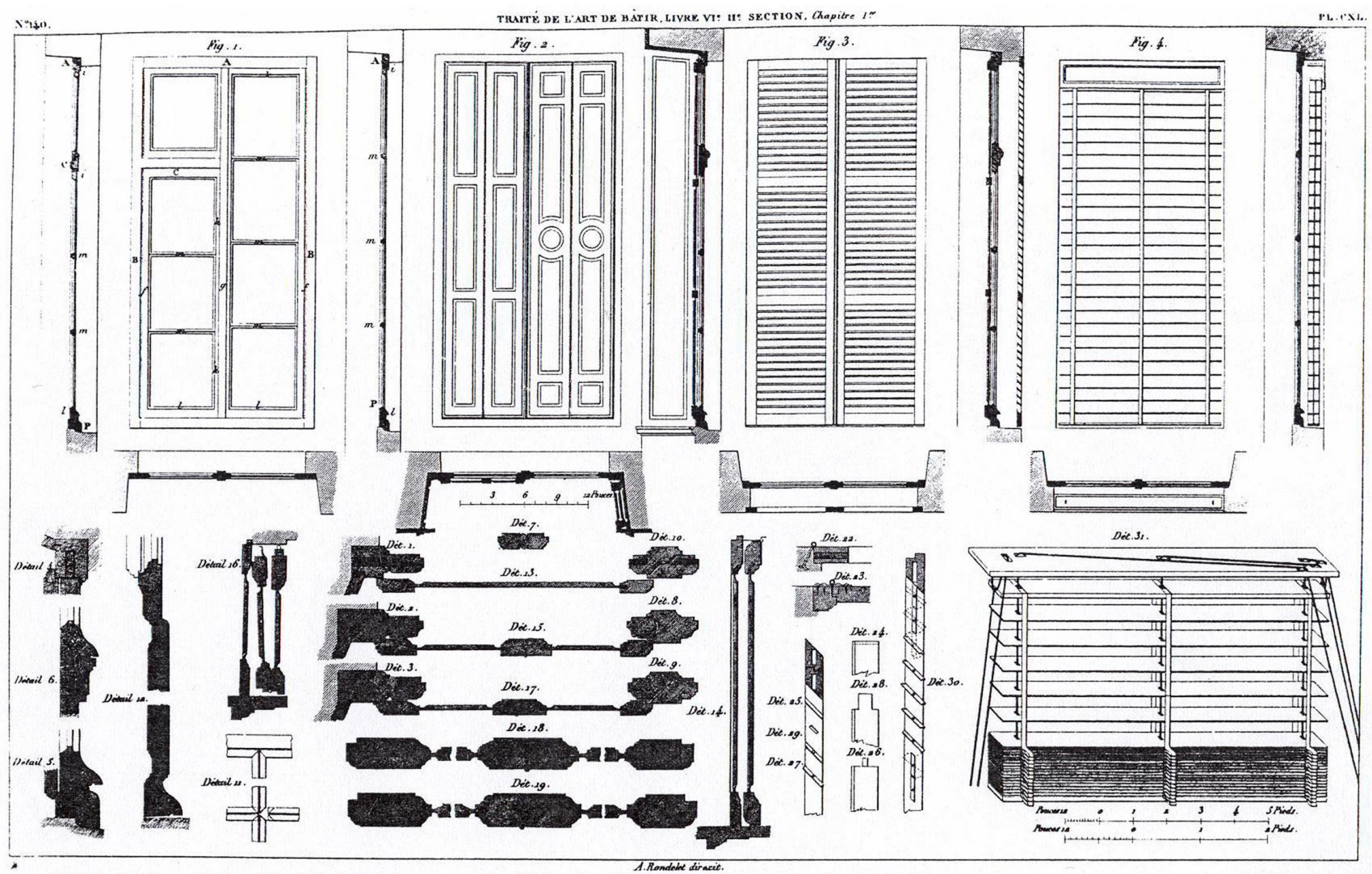

Figura 1. Rondelet, J. Traité théorique et practique de l'art de bâtir. 
específicamente la persiana enrollable de lamas con enganche continuo, no orientables ni proyectables que apenas han sabido integrarse en una organización coherente del hueco. Un diseño de persiana de prestaciones muy pobres donde la simplificación del elemento ha ido en detrimento no sólo del control medioambiental sino también de la riqueza espacial, lumínica y visual de los espacios interiores.

La persiana enrollable es un elemento fundamental en esta transformación del hueco. Su aparición se produce en los años de plena vigencia del hueco tradicional, como alternativa a la persiana de librillo, a la que opone muchas ventajas, desde la maniobra interior al aislamiento, regulación o seguridad, y veremos que ofreció soluciones espléndidas, tan generalizadas como su precedente plegable. Es después, ya generalizada la construcción con esqueleto, cuando parece perder todas sus ventajas y convertirse en la fórmula rutinaria e ineficiente que hemos descrito.

La revisión de la persiana enrollable y de su evolución histórica puede ayudarnos a devolver al cerramiento y al hueco esa eficacia y complejidad pérdidas y acercarnos a la necesaria tipificación de nuestras soluciones.

Las primeras persianas enrollables surgen en Inglaterra a principios del s. xIx con la revolución industrial, asociadas a las nuevas posibilidades del vidrio y del hierro, pero también en plena vigencia de la construcción mural.

\section{REVISIÓN DE LA PERSIANA ENROLLABLE}

\subsection{Inglaterra}

A comienzos del siglo xix la mejora de las condiciones de habitabilidad origina la revisión del diseño del hueco, considerando diferentes aspectos como la iluminación, el control térmico de los ambientes o la salubridad del aire interior. La concepción de los huecos de fachada comienza a transformarse en su proporción, en el diseño de la carpintería, de sus filtros y de los materiales que lo componen. Las carpinterías dentro de sus hojas incorporan vanos de lamas orientables que permiten la ventilación, proponiéndose incluso de vidrio para mantener la estética y nitidez del hueco (Figura 2). Sin embargo, el vidrio que permite gran transparencia es considerablemente frágil, muy delgado y por tanto sin cualidades aislantes ni control del espectro solar, de modo que la necesidad del control climático se resuelve mediante la incorporación de filtros escamoteables: postigos y persianas.

La necesidad de cubrir grandes huecos implica el problema de soportar el gran peso de los elementos de filtro y su dificultad de manejo, lo que impulsa la aparición de la persiana de cuerda formada por lamas que se enrollan en forma de persiana giratoria, llamada revolving-shutter donde un eje soporte del faldón gira gracias a ruedas dentadas sin apenas esfuerzo. La facilidad y ligereza que presenta el sistema desplaza la utilización de los postigos e incluso de las cortinas.
THE BUILDER.

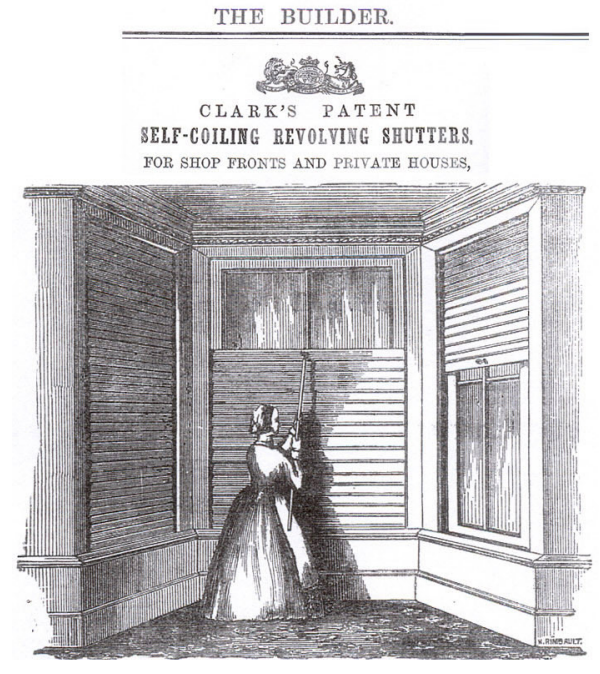

BALLLIE'S SEIDE-VALVE TRANSPARENT VESTILATOR.

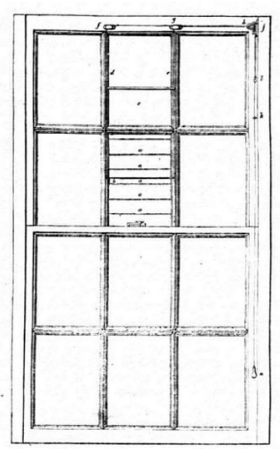

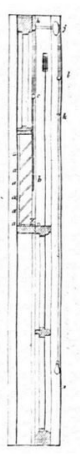
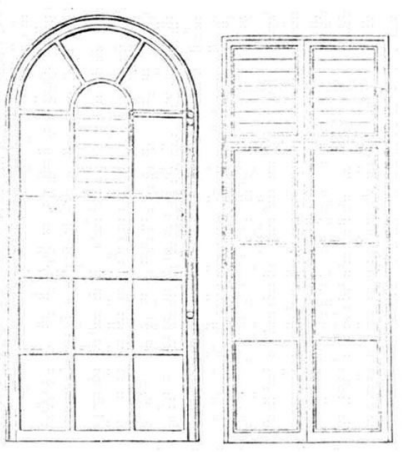

Figura 2. The Builder. Ventilación en las ventanas y revolving-shutter. 
La primera patente se puede fechar en 1818, Mr. Michel y Whiting, pero será en 1836 con Mr. Bunnet y Corpe (3) cuando se logra un avance significativo del sistema en su mecanización gracias a la incorporación de engranajes de dientes de gusano que permiten mediante el giro de plano del movimiento alcanzar la mano del usuario y facilitar su maniobrabilidad.

Los edificios públicos y los locales comerciales son los primeros en incorporar estas primeras revolving-shutters premiando la seguridad, confort y manejo fácil y ligero del sistema (ejemplos: banco Messrs y Conservative Club-House en Pall Mall).

Los anuncios en revistas de arquitectura elogian la solución por su rapidez de uso sin tener que abrir las ventanas y por lo tanto evitando el contacto del aire frío del exterior. Además enfatizan su carácter escamoteable, ya que su recogida en bombo minimiza el espacio de almacenaje sin entorpecer la composición de la fachada, a diferencia del acopio visible de los tableros en las persianas de librillo o las contraventanas de la época.

A partir de 1845 aparecen nuevas patentes que simplifican y mejoran la durabilidad del sistema, reduciendo engranajes y mejorando la conexión entre tablillas tanto de madera como metálicas (John Clarks, Snoxell,...). Se plantean gran variedad de diseños con distintas disposiciones del sistema en relación al hueco con el objetivo de mejorar las demandas ambientales, presentándose persianas exteriores e interiores y con diversas posibilidades de desplazamiento del faldón.

Con el clima frío inglés las persianas pueden facilitar o evitar la radiación solar según su posición. En el caso de las persianas interiores de madera, éstas absorben calor y se convierten en un difusor durante las horas de sol gracias al efecto invernadero, actuando cómo contraventana y filtro aislante frente al frío reduciendo la conductividad térmica. En cambio en las persianas metálicas interiores depende de su grado de reflexión que la radiación emitida, de alta frecuencia, atraviese el vidrio y actúe más como mecanismo de protección solar que como emisor de calor.
En cuanto al desplazamiento del faldón de la persiana se plantean ejes verticales y ejes horizontales (Figura 2). Las primeras se asemejan a las persianas de librillo en su movimiento y control solar vertical, siguiendo la composición de la carpintería y facilitando su practicabilidad. Las de eje horizontal se proponen con enrollamiento superior o inferior. La posición superior del eje facilita el movimiento por gravedad, sin embargo, las de eje inferior aporta mayor control lumínico y visual. El hecho de enrollar la persiana en la parte inferior permite dejar la parte superior sin cubrir, facilitando la entrada de luz y su reflejo en el techo, proporcionando una iluminación interior difusa y directa, facilitando la ventilación.

Una condición que no se menciona en los anuncios es la posibilidad de controlar las vistas y de ver sin ser visto. Tampoco aparece en las primeras patentes la posibilidad de movilidad de las lamas.

\subsection{Francia}

Las persianas inglesas no se dan a conocer significativamente en el resto de Europa hasta la Exposición Universal de París de 1867 , donde se exhiben patentes francesas derivadas de las inglesas (con mención especial a John Clark) (4). A partir de ese momento se produce una gran difusión en revistas especializadas de arquitectura, como Gazzette des Architectes et du batiment o Nouvelles Annales de la Construction (5), donde los sistemas se detallan de manera gráfica, describiéndose en alzado, planta y secciones, a distintas escalas, los mecanismos que los conforman. En ellos la atención se centra en los mecanismos y no en las demandas del sistema, el concepto de persiana se diluye para dar paso al de cierre donde grandes superficies consiguen unos paramentos rígidos, sólidos y seguros.

Los mecanismos que se presentan parten del cilindro de eje en la parte superior de la abertura planteando diferentes manejos del sistema; bien por varillas vinculadas o por cadenas conectadas a ruedas dentadas y con faldones enrollables con distintas conexiones entre lamas o con planchas onduladas continúas volviendo a la idea de postigo. En este sentido aparecen otras patentes que parten del deslizamiento en paralelo de tramos de plancha ocultándose detrás de un elemento embellecedor (Figura 3).
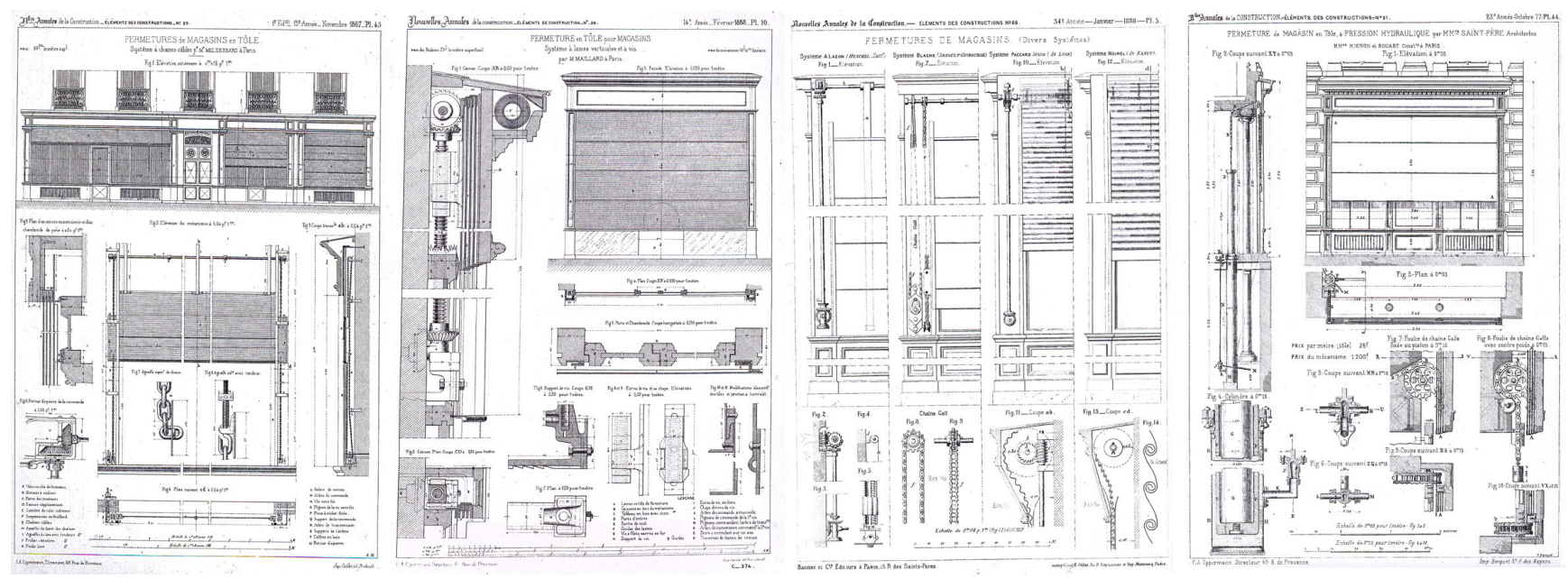

Figura 3. Nouvelles Annales de la Construction. Melzessard 1867; Maillard 1868; Lazon, Blanché, Paccard, Noirel1888 y Saint-Pere 1877. 
Sólo se publican dos patentes de persianas como dispositivos de control medioambiental, el sistema Cheyne y Cairol, los cuales tienen interés por su mecanización y maniobrabilidad desde el interior (Figura 4). El primero presenta una persiana enrollable de madera heredera de las inglesas donde plantea la posibilidad de controlar el espacio entre lamas para permitir las vistas y la entrada de luz a su través. El segundo mecaniza la persiana librillo a través de una guía corrugada por la cual se deslizan las hojas plegándose en acordeón a semejanza de las españolas.

\subsection{España}

La persiana enrollable llega a España aproximadamente en 1900 a través del empresario Ramón Múgica, propietario de una fábrica industrial de carpinterías en San Sebastián, quién adquiere la patente de introducción de las revolving-shutter inglesas (6). Es en 1909 cuando su difusión y reconocimiento se extiende por todo el país compitiendo directamente con las persianas de librillo por sus ventajas constructivas, medioambientales y de uso, introduciendo la capacidad de cierre.

En el catálogo de los Herederos de Ramón Múgica, HRM, quedan de manifiesto las prestaciones exigidas a las persianas y cierres de la época y las mejorías frente a los inconvenientes y molestias de las «antiguas» de librillo.

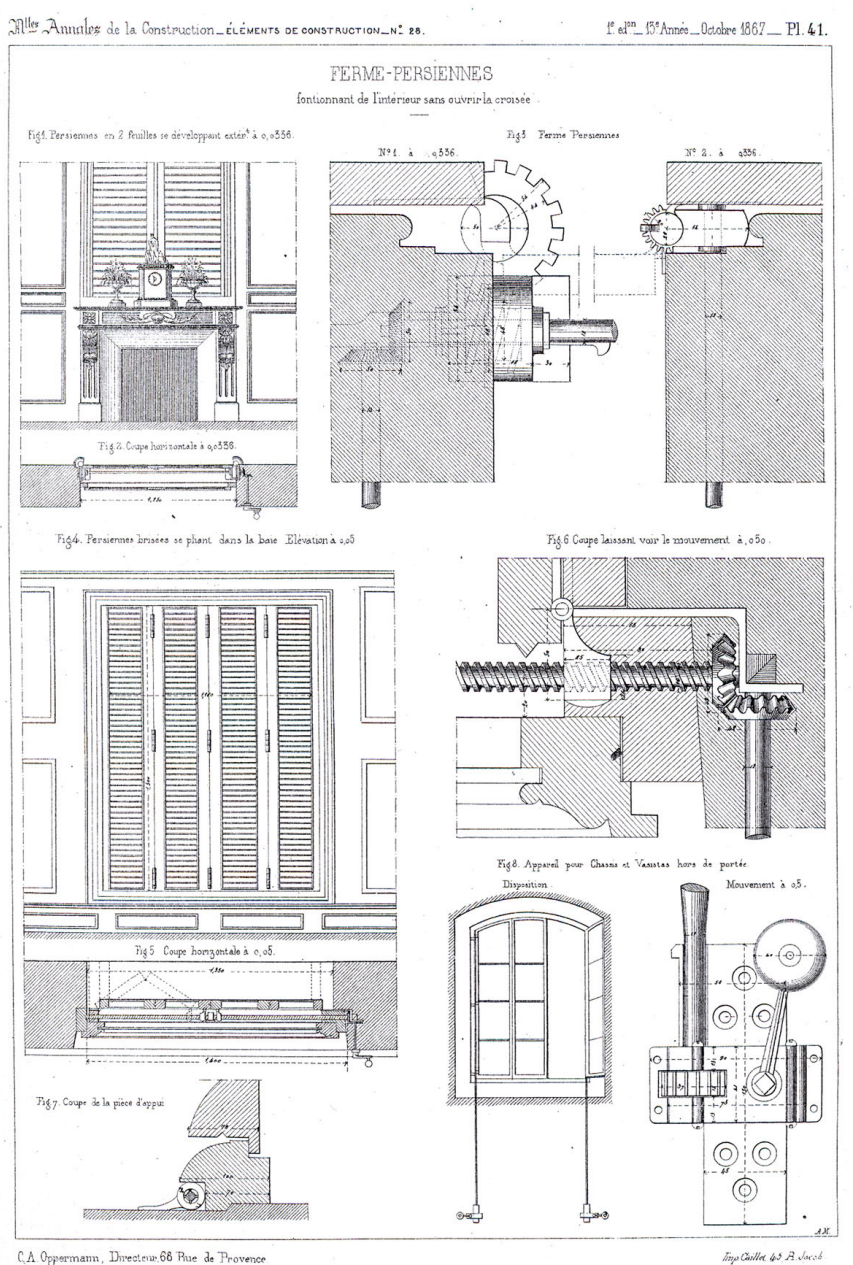

La persiana se inserta en el hueco de la fachada en diversas posiciones y encajes en el grosor del muro.

Las ventajas y aplicaciones de las persianas se introducen en tres bloques. Manejo y confort (la manipulación desde el interior de la persiana sin fatiga con distintos aparatos de maniobra y sin necesidad de abrir la ventana). Inserción y composición (la problemática de la implantación y practicabilidad del librillo en huecos de grandes dimensiones y con dinteles de arco queda resuelta por su deslizamiento vertical y su independencia de la hoja de fachada liberando totalmente el hueco. La preocupación por la composición de la fachada y la lectura nítida del hueco juega a favor del nuevo sistema). Durabilidad y conservación (los herrajes de acero galvanizado o cobre propuestos no se oxidan).

En la comparativa no se menciona el control de luz ya que las persianas de librillo consiguen un mayor control solar de doble dirección. Pero en la voluntad de suplir la desventaja, el catálogo muestra hasta diez faldones con distintos perfiles de lamas con el objetivo de aumentar las posibilidades de control lumínico (Figura 5).

Los perfiles varían en sus dimensiones, tanto en altura para conseguir más o menos intervalos como en sus secciones rebajándose el grueso de la madera en tramos por donde filtrar

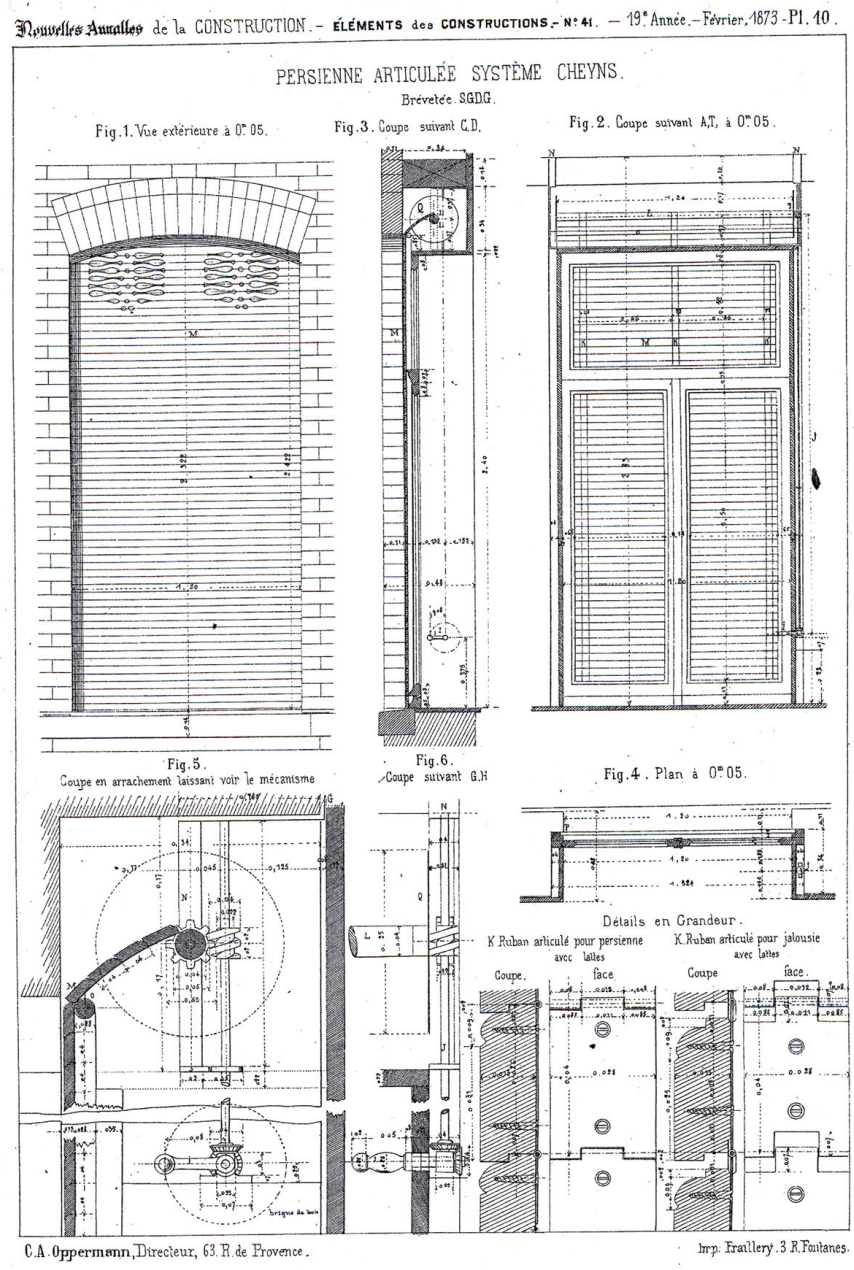

Figura 4. Nouvelles Annales de la Construction. Cairol 1867 y Cheyns 1873. 
la luz. Los enlaces entre lamas se presentan en hilo continuo o a través de eslabones encadenados permitiendo éstos últimos dar un juego de movimiento en el intervalo entre lamas consiguiendo «lamas móviles».

Con el objetivo de alcanzar un mayor control solar aparece la posibilidad de proyectar en compás el faldón hacia adelante, como si de un toldo se tratase, a la manera italiana de los fraileros consiguiendo la protección en la doble orientación. También se vuelve a presentar la opción inglesa de la inserción del eje de giro en la parte inferior del hueco, mediante mecanismos de poleas y muelles compensadores, permitiendo la entrada de luz superior.

Es evidente que el control de luz es una prioridad, como la simplificación del sistema, pero también lo es la consideración del filtro como aislante al frio, ya que las contraventanas no aparecen en ningún detalle y en los anuncios de 1909 entre las ventajas de esta tipología de persiana aparece la supresión de postigos, avalando la doble función de protección solar y térmica.

\subsubsection{Antonio Gaudí}

En Cataluña, junto con los HRM los carpinteros Casas\&Bardes presentaron las persianas «rollables» a los arquitectos de mayor prestigio (Figura 6). Edificios en las calles principales del nuevo Ensanche, en esa época en construcción, adoptan en sus huecos y tribunas ésta tipología de persiana, al igual que los locales comerciales los cierres metálicos.

Casas\&Bardés fueron los carpinteros de Antoni Gaudí, y conjuntamente proyectaron con anterioridad a estos años mecanismos enrollables (7). La preocupación de Gaudí por el control solar, la salubridad del espacio interior y el confort derivó en ingeniosas soluciones para los huecos de fachada, como la galería del Palacio Güell, 1886-1888, con control de las lamas desde el interior mediante engranajes, cadenas y ruedas de gusano, o las galerías de la casa Calvet, 1898-1900, en la fachada al patio de manzana con persianas de librillo guiadas con un pasamanos ondulado a semejanza de la patente francesa Cheyne. Gaudí estaba al tanto de los sistemas constructivos y de los escritos de Viollet-Le-Duc (Figuras 7 y 8) (8).
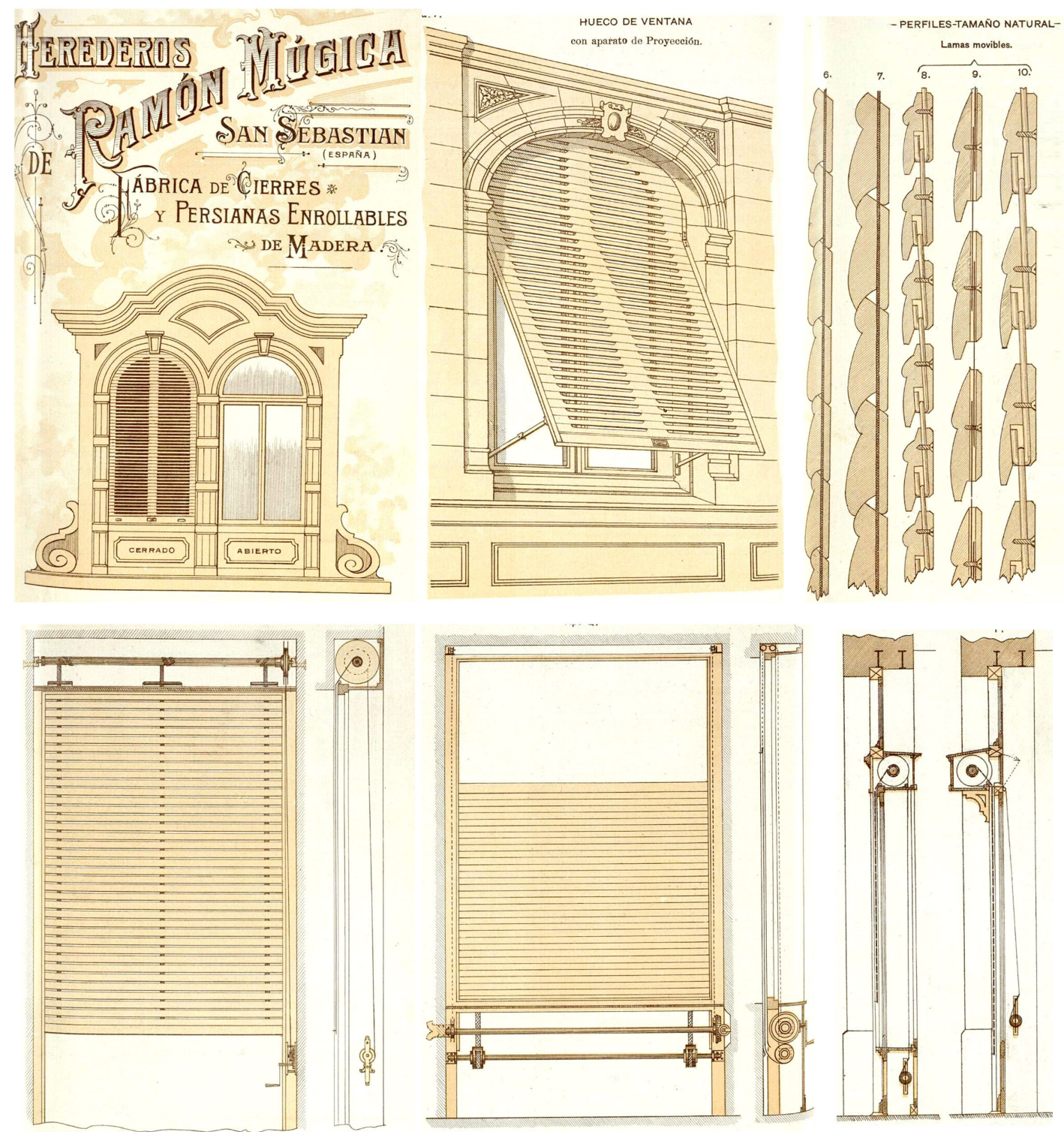

Figura 5. Persianas. Catálogo: Herederos Ramón Múgica. 


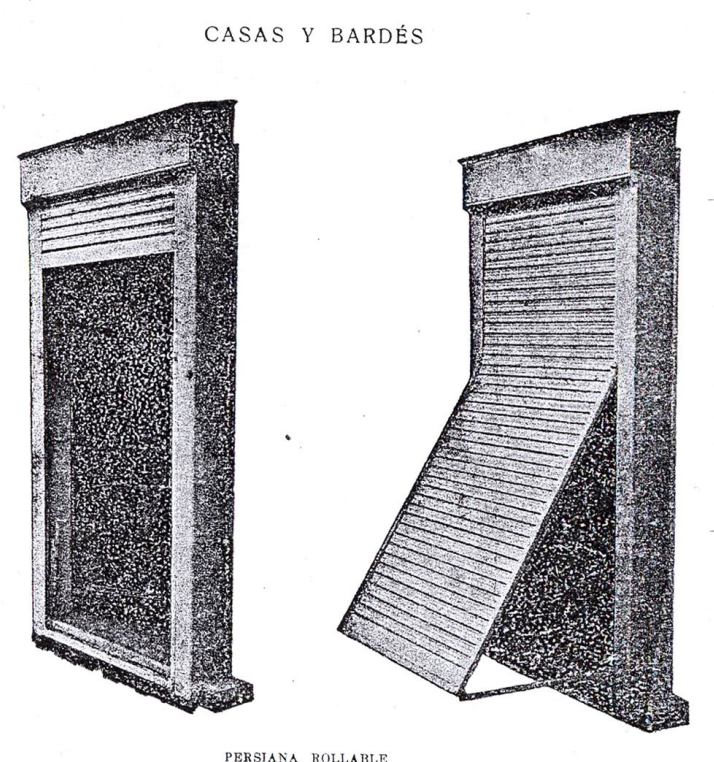

PERSTANA ROLLABLE
Casas y Bardés CONSTRUCTORES de

PARQUETS TECHOS Y ARRIMADEROS de madera, á precios reducidos. PERSIANAS rollables, propias para aberturas, balcones y galerías; con las mismas se consigue la supresión de los postigos. PATENTE DE INTRODUCCION

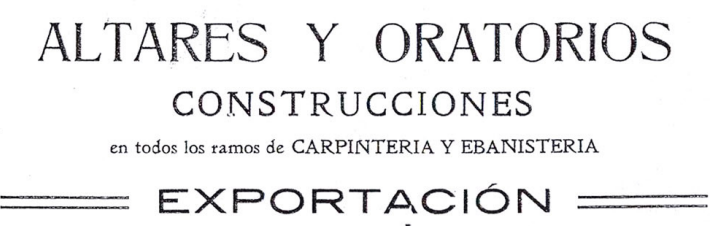

TALLERES Y DESPACHO: Díputación, 119 y 121 TELÉFONO 3386

FABRICA: Casanovas, 23

CATALOGOS, DET ALLES Y PRESUPUESTOS

los mandamos á quien nos lo solicite

MUESTRAS AL NATURAL en los talleres

BARCELONA

Figura 6. Anuario de Arquitectos de Cataluña. Casas\&Bardés.
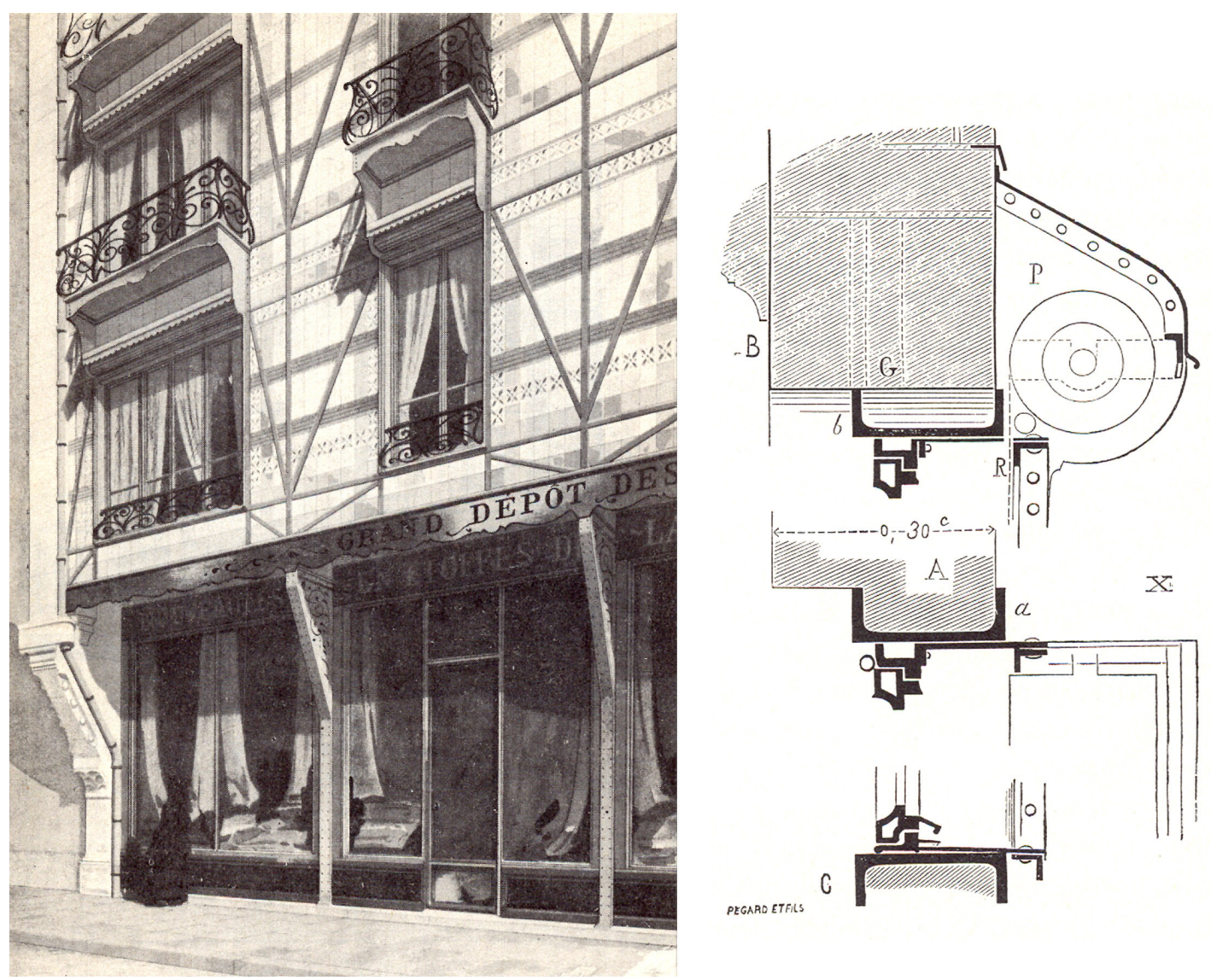

12

PEGARDETFIS

Figura 7. Le Duc, V. Entretients sur l'architecture. 1863. 


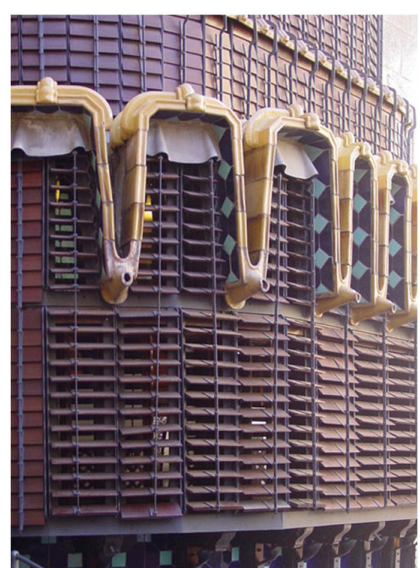

Palacio Güell

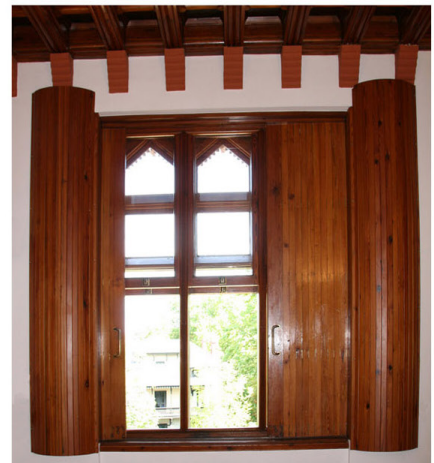

El "Capricho"

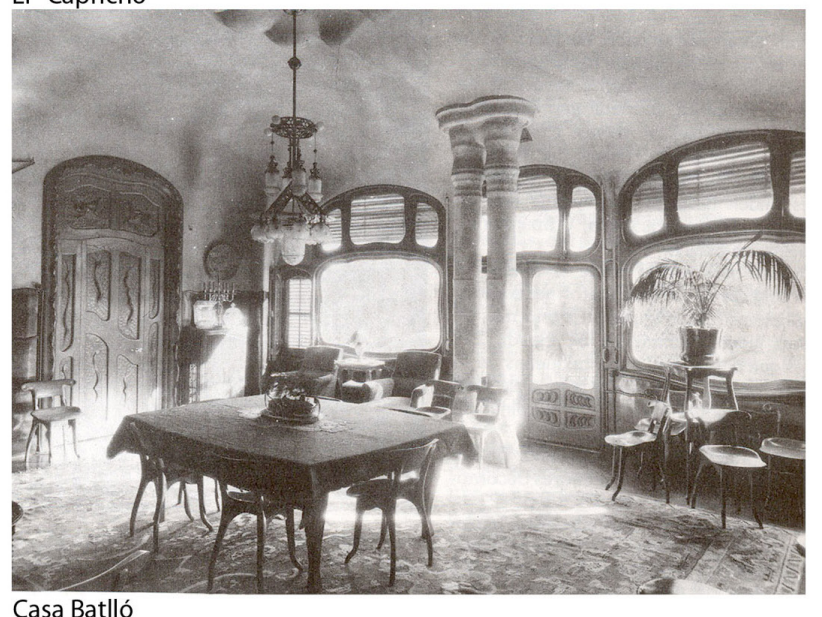

Casa Batlló

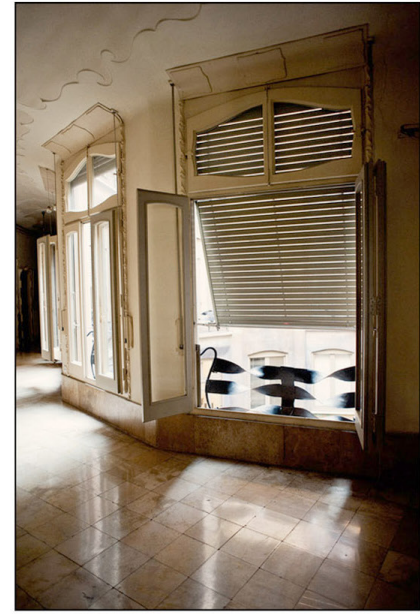

Casa Milá

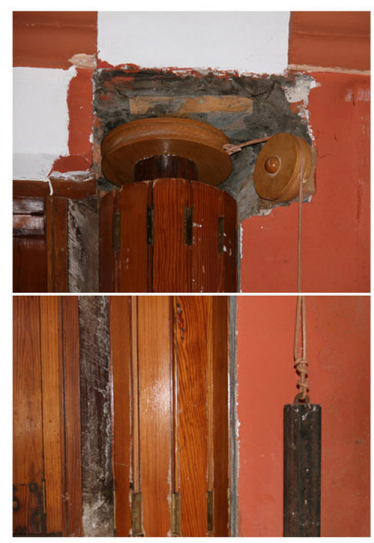

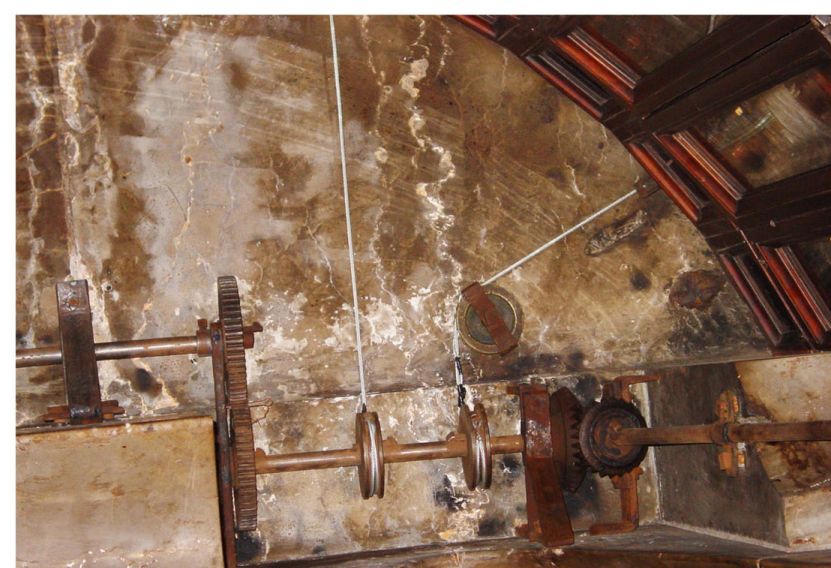
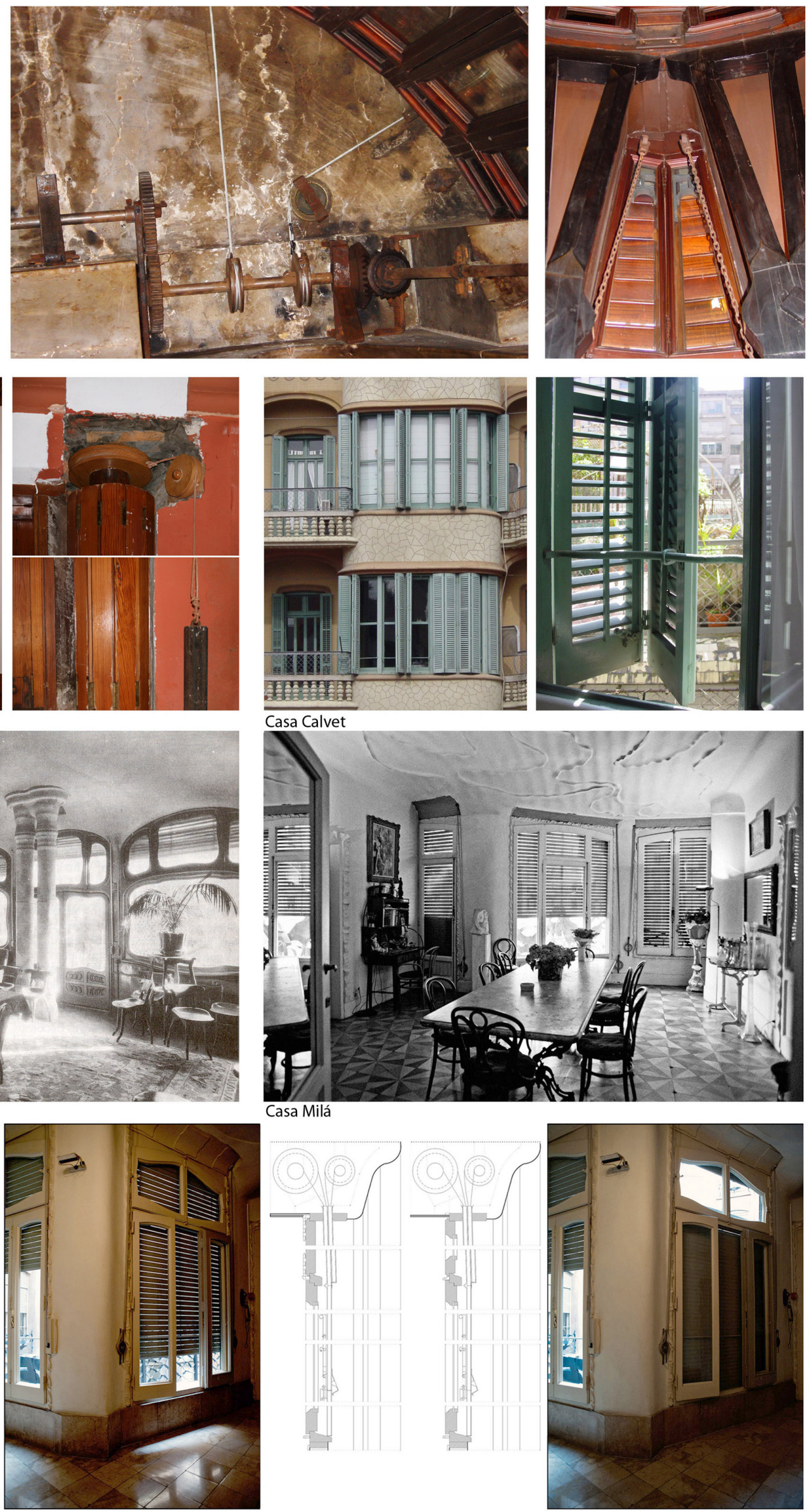

Figura 8. Martí, N. Las persianas de Gaudí. 
La primera obra que Gaudí proyecta con un sistema enrollable es la residencia de verano «El Capricho», 1883-1885, en Cantabria donde aplica el sistema a una contraventana con el eje de giro vertical. Si bien era conocedor de la arquitectura francesa no se puede probar que conociese las patentes inglesas. Sí que su propuesta de lamas y eje vertical es semejante a éstas pero la mecanización se simplifica evitando cualquier engranaje y utilizando en el sistema poleas y contrapesos para facilitar la maniobrabilidad aligerando el esfuerzo del deslizamiento.

En 1904-1906 en la casa Batlló, Gaudí incorpora la primera persiana enrollable mecanizada desde el interior en un hueco de dimensiones mayores a metro y medio con ventana de hoja única oscilo-batiente y no accesible desde el exterior.

Aún no normalizado el uso de la persiana enrollable en Barcelona, Gaudí proyecta en la casa Milá, 1906-1910, una fachada no portante con huecos de dimensiones mayores a los dos metros, con ventanas y balconeras de carpintería de librillo y persianas enrollables proyectables (9). Pero su ingenio en la reinvención de la persiana resulta espléndido en las balconeras de las fachadas del patio, donde son importantes la privacidad y el control lumínico. Gaudí propone no solamente la proyección de los faldones dividiendo la guía para que pueda realizarse el movimiento de compás por encima de la barandilla sino que dobla la persiana: el hueco dispone de dos persianas independientes, cada una con sus sistemas de cinta y bombo, un faldón cubre la parte superior de la balconera siguiendo la composición del despiece de la carpintería de la ventana y el otro cubre la parte inferior. Esta solución de faldón fragmentado permite multiplicar las posibilidades de control sin complejidad añadida. Los bombos de persiana se sitúan en el cielo raso sin interrumpir la piel exterior de la fachada, siendo fácilmente registrables.

\subsubsection{La integración de la persiana en el cerramiento}

La obra de Antonio Gaudí es una expresión destacada de un proceso generalizado de integración de la persiana enrollable en el cerramiento en los años en torno al cambio de siglo. La construcción con muros portantes está entonces generalizada, y comienzan a realizarse muchos edificios con estructura metálica, caracterizados por cerramientos de fachada de gran espesor en una o dos hojas, y también por una nueva libertad en la composición del hueco, que característicamente comienza a ensancharse. La persiana enrollable logró incorporarse en estos sistemas constructivos, mientras el librillo resultaba ya menos eficiente.

Por un lado la persiana estaba ya resuelta como producto industrial -que ofrecía además las diferentes prestaciones que hemos descrito- y por otro se había logrado incorporarla en la organización del muro, fuera o no portante con los espesores característicos de la época.

Se ensayaron diferentes soluciones igualmente convincentes, como alojar el tambor en el doble techo (Gaudí) o colocarlo al exterior, de modo que se evitaba toda discontinuidad en el muro. Esta última solución -dibujada por Violet-le-Duc con la caja de persianas formando una moldura sobre el huecocuenta con realizaciones espléndidas ya a comienzos de siglo como la Casa Comalat de Pupurull, 1906. La colocación exterior del tambor estaba también presente en los catálogos de HRM (Figura 5).
Pero la solución de mayor éxito fue integrarla en el propio espesor del muro, acompañando al cargadero y descolgando la fábrica por delante del tambor, siempre con un espesor superior al medio pie. Este mismo espesor era el habitual en la hornacina que aloja el radiador, de modo que la incorporación de la persiana no restaba integridad al paño mural. Con esta solución llegamos hasta muy avanzado el siglo xx, tanto con muros portantes como en la Casa de las Flores de Zuazo 1931 (Figura 9) (10) o en muros de cerramiento de dos hojas (Ciudad Universitaria de Madrid).

Los problemas vendrán de la mano de la pérdida de espesor del muro de cerramiento y en concreto de la generalización de la solución de dos hojas de fábrica con un espesor de medio pie máximo en cada una de ellas. Este tipo de muros presentaban ya el conflicto de la pérdida de la cámara de aire en las hornacinas o en los soportes de fachada que hacían necesarias las mochetas con los consiguientes problemas de pérdida de aislamiento- y sobre todo el conocido problema de su encuentro con el forjado, donde el muro perdía todas sus características. Ahora el tambor de la persiana iba a añadir un conflicto más, pues o vuelve a perderse la cámara y el aislamiento o el tambor invade el espacio interior. Con la persiana enrollable el muro pierde definitivamente su integridad, con las conocidas patologías derivadas de ello.

De hecho hasta la normativa iba a «santificar» una solución no resuelta. En 1974 aparecen las primeras Normas Tecnológicas de la Edificación, NTE, que reflejan la generalización de la persiana enrollable. Los elementos del hueco que consideran son la carpintería, el vidrio y las defensas, y en este último epígrafe aparecen las persianas (Figura 10) (11) reduciéndose todo el equipo de la ventana a éstas y considerándose como elemento de cerramiento y de protección. Estas normas regulan el diseño, cálculo, construcción, control, valoración y

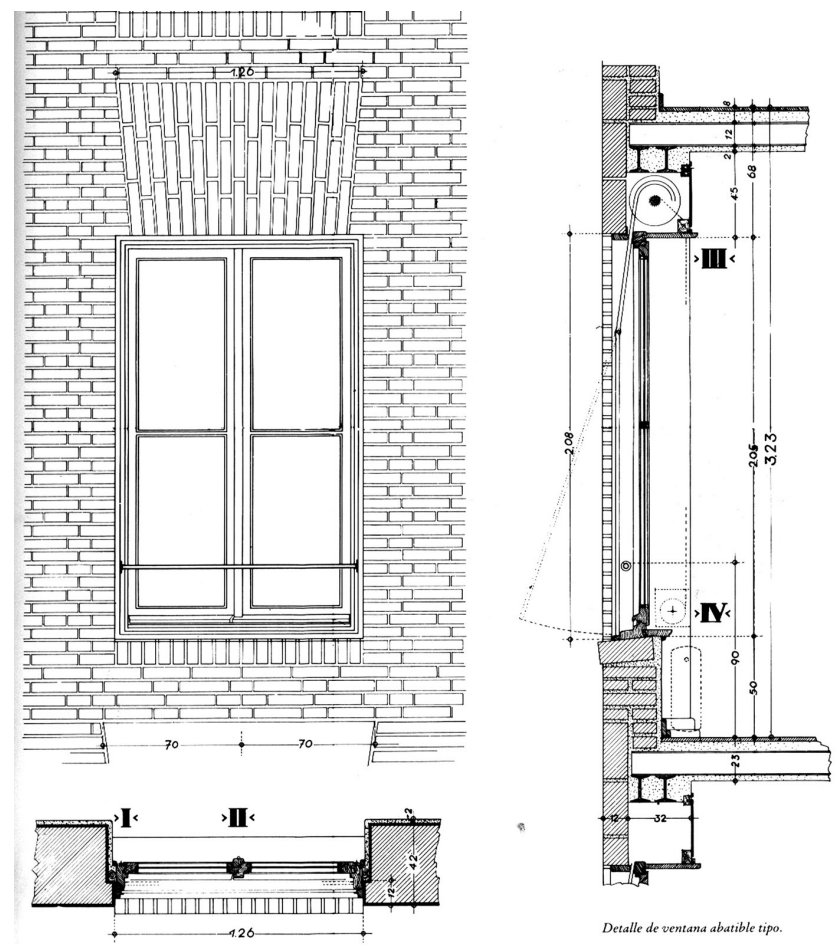

Figura 9. Zuazo,S. COAM. 


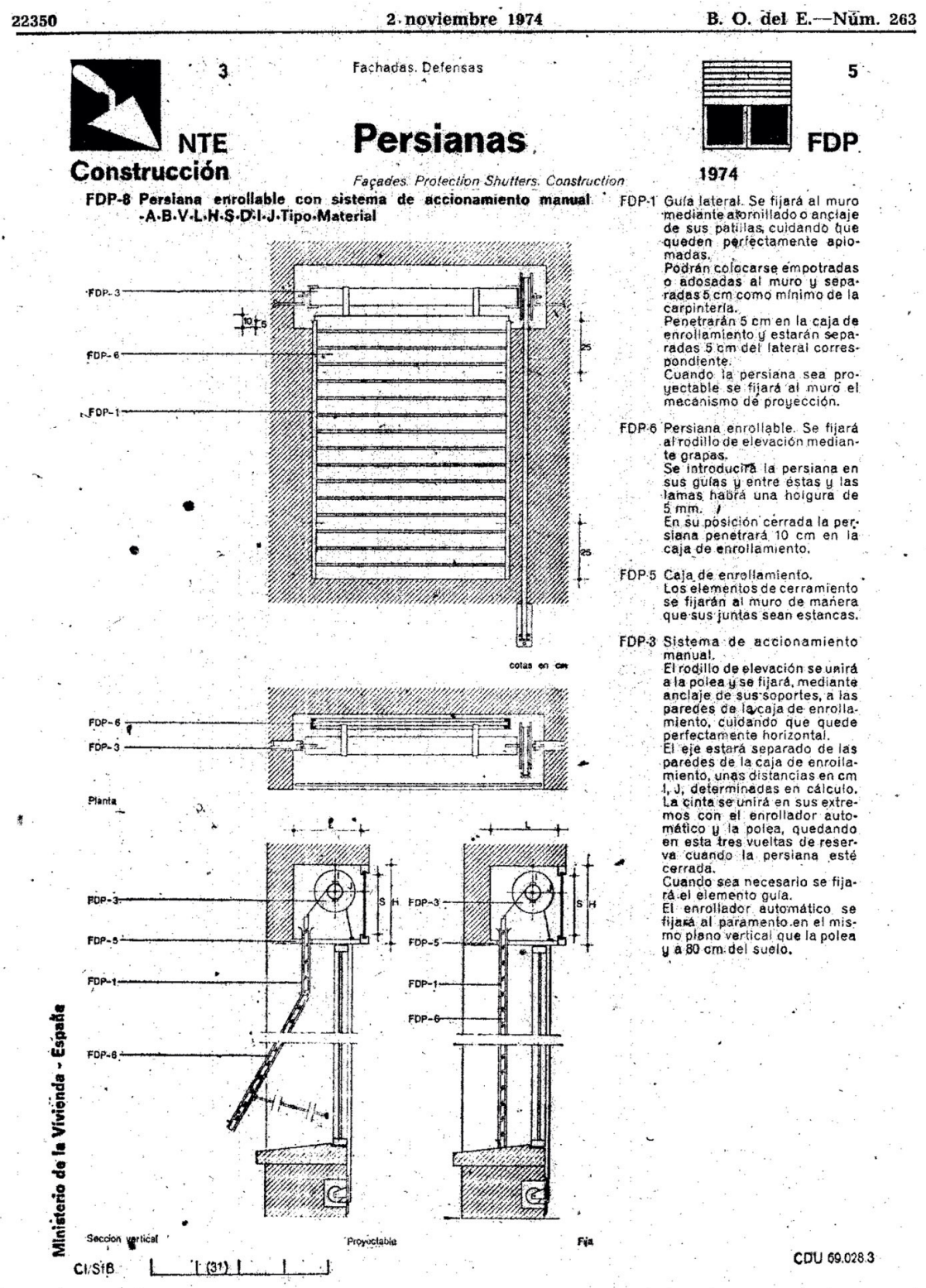

Figura 10. NTE-FDP/1974.

mantenimiento de las persianas, clasificándolas entre enrollables y de celosía, incluyéndose en esta última categoría de lamas orientables con marco practicable, como son las persianas de librillo. No se consideran las persianas de cuerda aunque en las enrollables se incorpora la posibilidad de proyectar en compás el faldón.

En la norma se reconoce no sólo la madera como material apto para las lamas sino también el aluminio y el PVC, especificándose en cada caso las medidas mínimas y máximas del sistema y sus elementos. En el caso de las persianas enrollables se plantean dos soluciones de faldón con resultados totalmente opuestos de control lumínico y visual, uno con uniones entre lamas mediante ganchos o flejes -que permite tener un haz de luz continuo horizontal- y otro con uniones mediante ensamblaje continuo -que obtiene un cerramiento con pequeños agujeros de luz-. Ahora bien, los detalles mostraban una sección que ocultaba el tambor, lo que no se correspondía con los grosores de fachada de la época, o al menos no indicaba como resolverlo.
Las mejores soluciones de los 70 fueron en realidad las que aumentaban el espesor de la cámara de aire o de la hoja exterior para resolver todas las heterogeneidades del muro, incluyendo el tambor y medio pie pasante por delante de él. Era la solución de sobredimensionar el cerramiento que caracterizó las primeras obras de esqueleto y aún hoy se sigue planteando, como en las viviendas en Sabadell, 2003 de Moneo y Martinez-Lapeña (Figura 11).

Se ensayaron otras soluciones, por ejemplo con un muro de dos hojas según el sistema del cavity wall la hoja externa podía prolongarse frente al canto de forjado y el tambor de persiana. Esta técnica no fue general nunca en nuestras latitudes pero encontramos interesantes ejemplos derivados de ella, como las viviendas de Lamela en la calle Segovia (12).

En Cataluña -más experimental en aquellos años y más pendiente de Italia- se planteó con cierta frecuencia la colocación de la caja de persianas por el exterior del cerramiento, especialmente en la obra de MBM (Figura 12) (13), la primera 

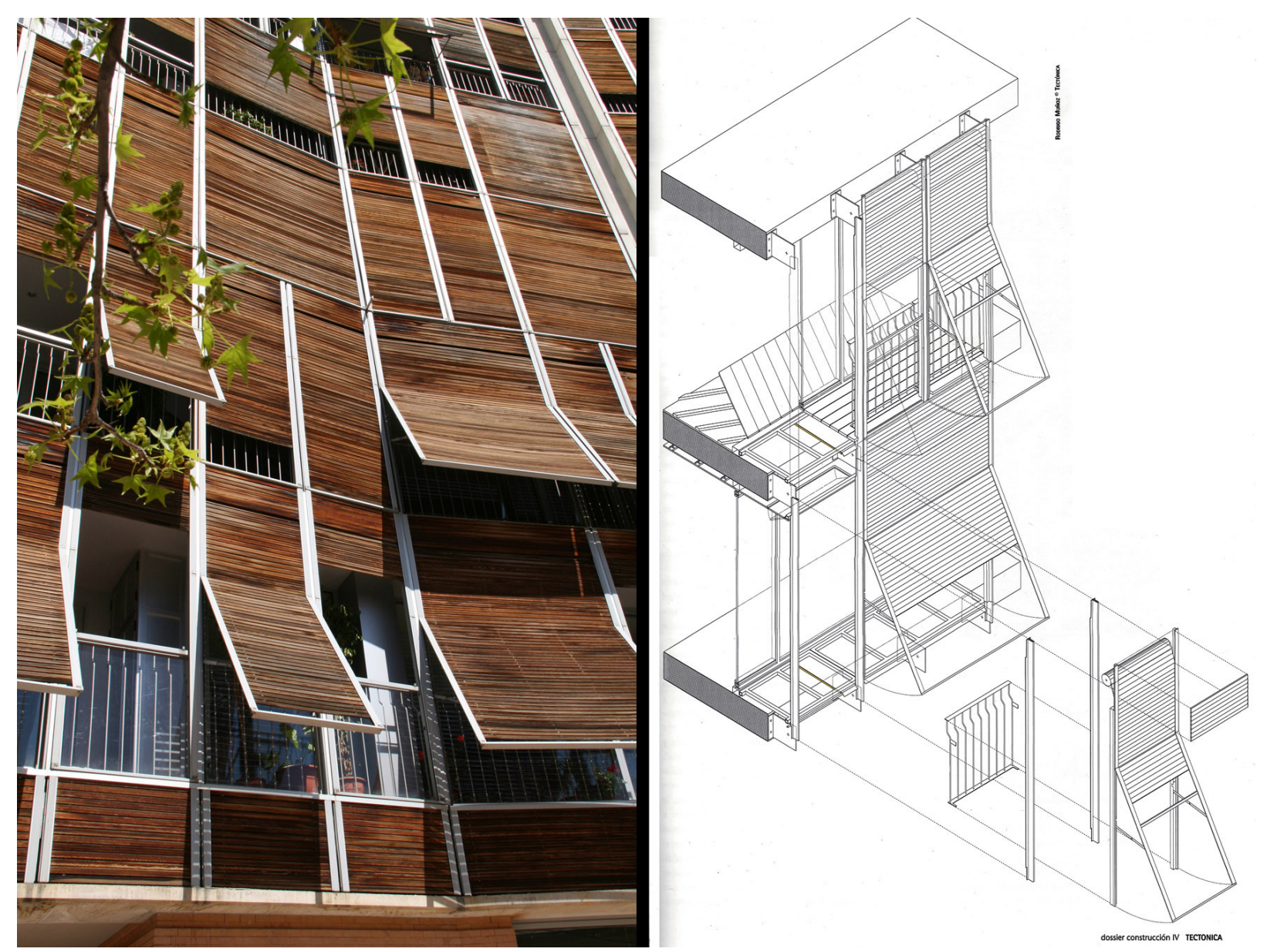

Figura 11. Detalle. Moneo, R y Martinez-Lapeña. Tectónica, 20. Muñoz, R.
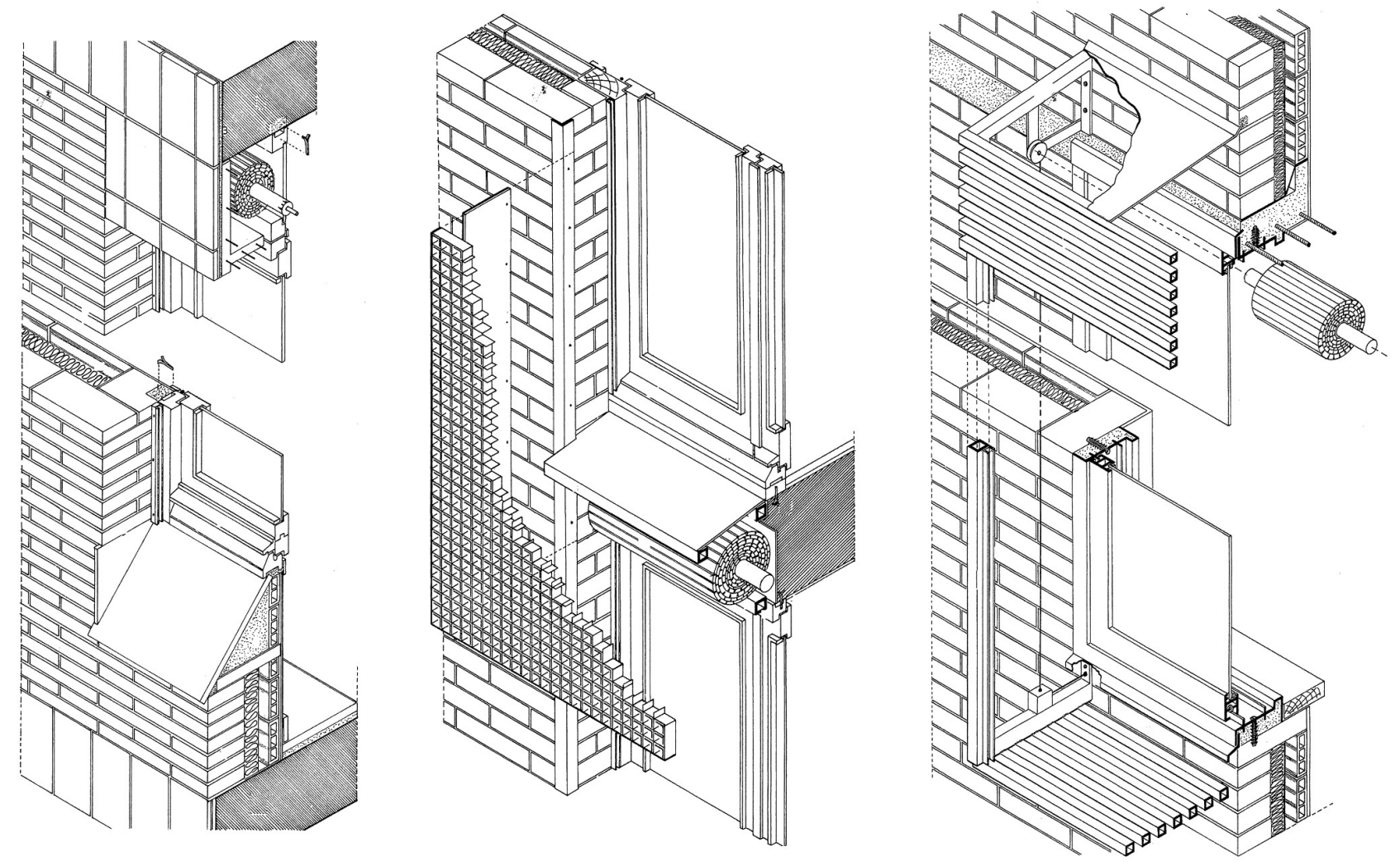

Figura 12. Permanyer, E. MBM. 
de las soluciones sugeridas por los catálogos de HRM. En la misma línea de independizar la protección solar del hueco, pero ya con una intención clara de crear un espacio de relación interior-exterior desplazando la persiana al plano exterior de los balcones o límites de porches. En teoría todo resultaba más sencillo y no dejaba de ser la solución natural al problema -equivalente a la del toldo y otros filtros exteriores desvinculados del hueco- pero nunca se generalizó (14).

Por último hay que citar la solución de llevar el hueco hasta el forjado superior, dejando visto el tambor y el canto del forjado, que fue la solución más general entre los arquitectos italianos (Ridolfi, por ejemplo).

La dificultad de integrar el tambor en el cerramiento explica que la persiana enrollable se asocie a una mala solución constructiva y que los arquitectos la eviten siempre que pueden durante los años en que predomina la construcción con fábrica de ladrillo en nuestro país.

\section{PERSPECTIVAS}

La persiana enrollable después de estos ensayos no ha cambiado mucho e incluso parece haber perdido prestaciones, sobre todo con el uso extendido de las lamas encadenadas que hacen del faldón una simple cortina.

En este sentido, las soluciones técnicas actuales centran su atención en resolver las limitaciones del sistema mediante la posibilidad de orientar las lamas y el control fragmentado del faldón para mejorar las prestaciones de control solar, lumínico y visual. La posibilidad de orientar las lamas equipara la solución de las persianas enrollables a las de librillo, permitiendo controlar no sólo las vistas sino la radiación solar. A mediados del s. xx, Gradhermetic presenta una de sus primeras patentes de persiana enrollable, que permitía orientar las lamas una vez bajado el faldón mediante la conexión de la cadena de unión de éstas a un mecanismo de engranaje en el interior de la carpintería (Figura 13) (15). En la actualidad el sistema se ha simplificado y mejorado mediante una lama guía que gira las demás. A la vez, la unión entre las lamas se realiza en su testa y dentro de la cavidad de la guía, liberando todo el vano del faldón de elementos verticales que interrumpen la visión desde el interior.

En cuanto a la fragmentación del faldón, la persiana propuesta por Warema «visio» permite dividir el faldón en dos, con la parte inferior cerrada y la superior abierta, consiguiendo un cerramiento de seguridad y una entrada de luz directa, respectivamente (Figura 13) (16). Esta patente reinventa la planteada por Gaudí en la casa Milá simplificando el sistema, ya que no sólo utiliza un único eje de soporte y guía sino que la independencia y adhesión entre los faldones se realiza a través de un sencillo gancho de conexión de acción mecanizada. Otra prestación que introduce Warema es la incorporación de un screen en el sistema, que tiene su propio eje de soporte en el interior del bombo, el cual dependiendo del color reflejará el sol, en colores claros hasta el $63 \%$, o hará de radiador solar, en colores oscuros, permitiendo tener vistas a su través (Figura 13).

En cuanto a la integración de la persiana en el cerramiento algunas realizaciones recientes recuperan aquellas soluciones de finales del siglo XX que hemos citado, como el montaje exterior, desvinculándose del grueso de la fachada o las nuevas posibilidades que abren las fachadas ventiladas, por ejemplo aprovechando el doble dintel con rotura de puente térmico de Keystone que incorpora el bombo (Figura 13) (17), y en general aquellas con el aislamiento externo para alojar el tambor de manera convincente.

Ahora bien, los mayores avances en persianas escamoteables se están produciendo en otras tipologías que tienen resuelta la limitación del bombo. Las persianas venecianas de RetroSolar (18) y Warema consiguen con gran facilidad fragmentar por tramos la manipulación de la orientación de las lamas para ajustar las necesidades de luz del espacio interior y conseguir efectos contrarios; conducir luz al interior en su parte superior a la vez que evitarla en su parte inferior.

Otra solución que se está planteando, de gran sencillez pero con grandes beneficios, es la persiana híbrida entre enrollable y veneciana; la persiana apilable y autoportante, con un cajón mínimo donde se repliegan las lamas, resolviendo el problema del bombo, y con una guía en la que discurre el mecanismo de pliegue que asegura el faldón ante acciones de viento e impactos, permitiendo su posición en el exterior (Figura 13) (19). La reducción del volumen del bombo permite una mejor inserción en cualquier plano de la fachada sin interrumpir la envolvente térmica y al quedar las lamas apiladas su geometría ya no depende del giro de enrollamiento y por lo tanto puede tener los pliegues que se requieran para responder mejor a las necesidades de control solar (Figura 13).

Nuevos avances del sistema presentan lamas de distintas geometrías dirigidas a controlar la incidencia y reflexión de la radiación. En las persianas enrollables la forma de la lama se encuentra limitada a su requerimiento de replegarse en el eje cilíndrico, en cambio en las persianas venecianas su libertad de geometría está permitiendo no sólo rechazar la radiación sino redirigir la luz hacia el espacio interior.

En estas soluciones, persiana veneciana y apilable-autoportante, se ha vuelto a plantear la cuestión de la posición de la persiana en relación al vidrio. Como elemento protector, realmente su posición exterior es más eficaz y más aún si dispone de un trasdós ventilado ya que siempre llega a absorber calor (Figura 13w-a). Al igual que en su posición intermedia, dentro de la cámara de aire entre vidrios, como elemento protector, necesita que el vidrio exterior sea sencillo para facilitar la salida de los rayos reflejados (Figura 13w-b). Ahora bien, en la posición en el interior permite tanto el mecanismo de protección como el de captación si se atiende a su capacidad de reflexión y absorción (Figura 13w-c).

Las persianas enrollables en la actualidad sólo se plantean en el exterior, y al considerarla como solución interior reaparece la problemática del bombo. Desvincularlo del grosor de la fachada vuelve a ser una respuesta, aunque de dificultosa concordancia con el espacio interior.

Si se piensa en una nueva perspectiva realista para las persianas enrollables, se podría considerar la persiana como elemento exento del hueco, incorporándose al panel exterior ligero o como doble fachada (Figura 13w-d). Ahora bien, la persiana apilable enmarcada dentro de un marco plano y delgado permite la posibilidad de desligarla del telar del hueco e incorporarse como un filtro en la hoja exterior de la fachada ventilada, mientras que las dobles fachadas pueden insertar las persianas en distintas posiciones protegidas del exterior, 

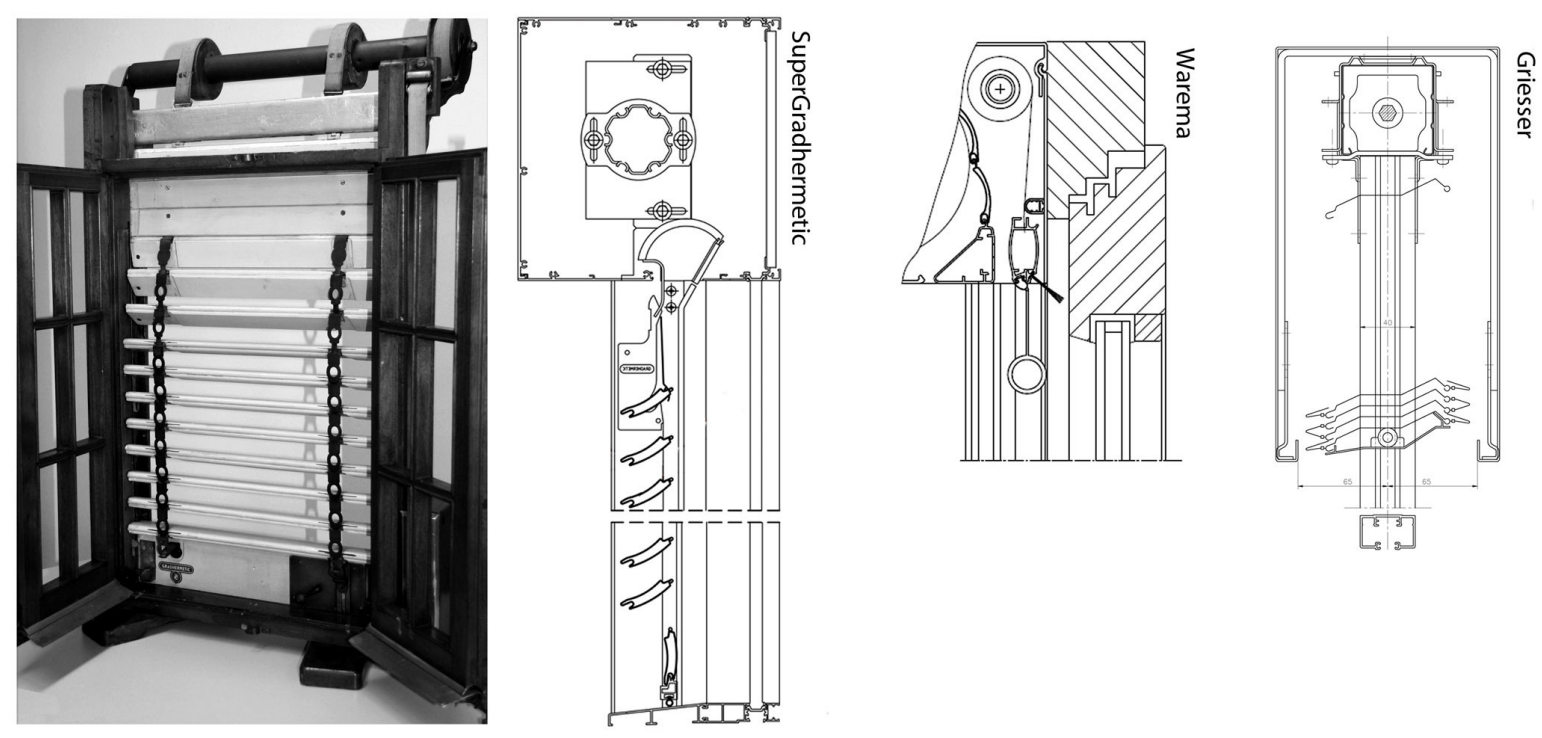

GRADHERMETIC
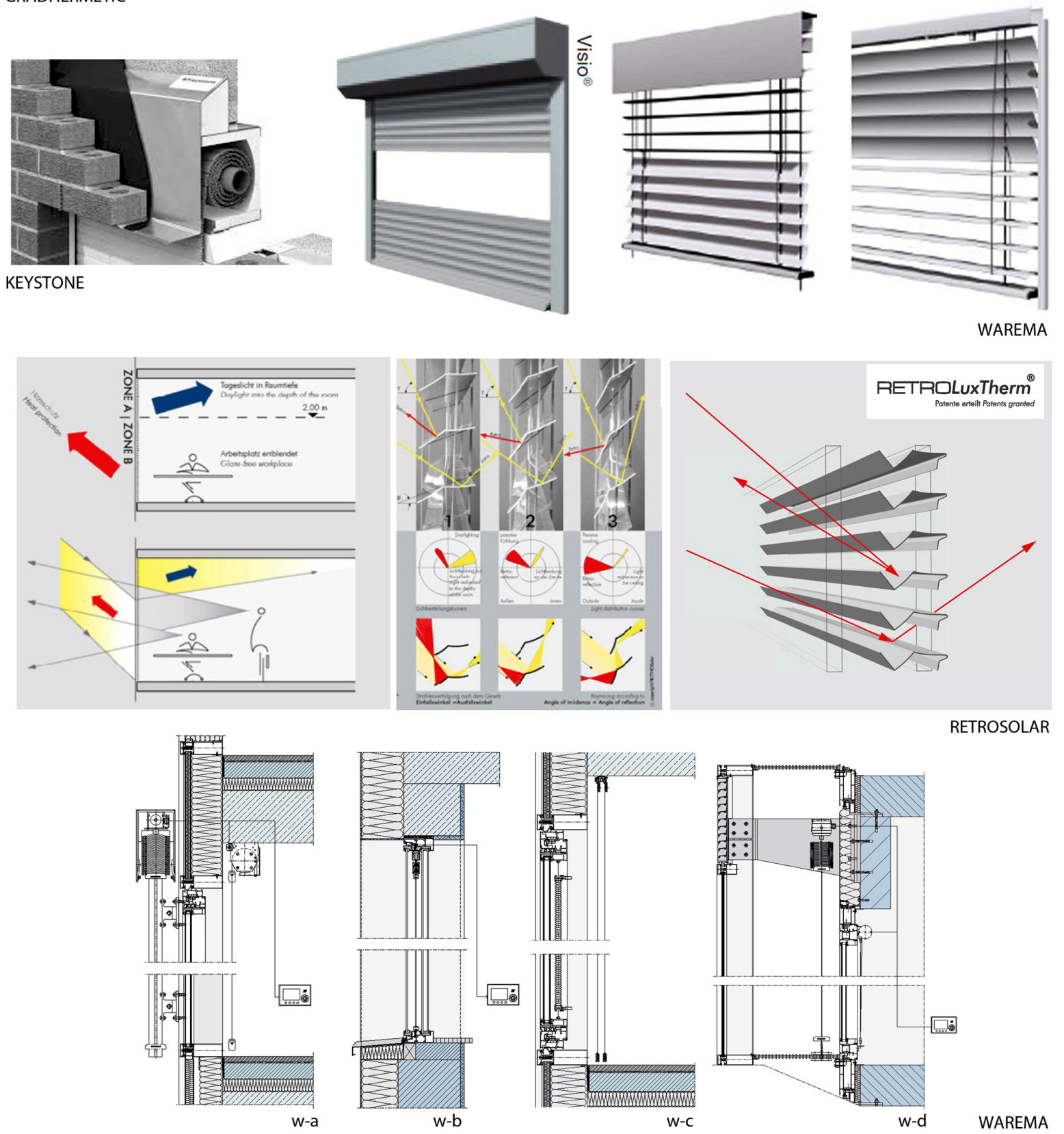

Figura 13. Gradhermetic, Griesser, Keystone, Retrosolar y Warema. 
permitiendo reducir sus secciones y aprovechando la subestructura de la hoja exterior. Por último si optamos por la concepción de la fachada como un sistema de paneles industrializados podemos concebir elementos similares a los realizados por Jean Prouvé incorporando en ellos persianas enrollables de los tipos citados.
En definitiva, se pueden planear soluciones integrales que unifiquen las necesidades de los sistemas de cerramiento, atendiendo tanto a una mayor industrialización como una nueva atención al control solar y termo-acústico, a la flexibilidad y maniobra en el control del ambiente.

\section{REFERENCIAS}

(1) Paricio, I. (1997). La protección solar. España: Ed. Bisagra.

(2) Paricio, I. (1996). El hueco en la fachada. Tectónica, Vol. 4

(3) Bunnet and Corpers V. Smith. (1845). Revolving shutters. The Builder, Vol.VIII: 315.

(4) Viollet le Duc, A. Morel (ed.). (1867). L'Exposition Universelle de 1867. En Gazette des Architectes et du Bâtiment. Paris.

(5) Oppermann, C. A. (Dir.). Nouvelles Annales de la Construction. Paris: Dunod Ed.

(6) GATEPAC. (1932). Persianas enrollables. AC. Documentos de Actividad Contemporánea, (7): 46.

(7) Martí, N. (2005). Las persianas de Gaudí, herramientas de luz (Tesis doctoral). Barcelona: ETSAB-Universitat Politècnica de Catalunya.

(8) González-Moreno Navarro, A. (1990). Gaudí, constructor (La materialización de una arquitectura singular). Informes de la Construcción, 42(408): 5-8, doi: http://dx.doi.org/10.3989/ic.1990.v42.i408.1423.

(9) González-Moreno Navarro, J.L. (2002). Después del año internacional Gaudí ¿Qué más sabemos de su obra? Informes de la Construcción, 54(481-482): 93-97, doi: http://dx.doi.org/10.3989/ic.2002.v54.i481-482.603.

(10) Ros, J.M. (2005). La fábrica de doble hoja en Madrid, un siglo de cerramiento moderno. Informes de la Construcción, 56(495): 57-71, doi: http://dx.doi.org/10.3989/ic.2005.v57.i495.455.

(11) Ministerio de la Vivienda. (1974, 26 de octubre). NTE-FDP/1974 Fachadas. Defensas. Persianas. Boletín Oficial del Estado, $\mathrm{n}^{\mathrm{0}} 257$. España.

(12) Lamela, A. (2005). La sostenibilidad, un reto global ineludible. Informes de la Construcción, 57(499-500): 55-65, doi: http://dx.doi.org/10.3989/ic.2005.v57.i499-500.482.

(13) MBM Arquitectes. Martorell, J., Bohigas, O., Mackay, D. http://www.mbmarquitectes.cat/.

(14) Permanyer, E. (1981). El detall constructiu a la pràctica de la professió. Barcelona: COAC.

(15) Gradhermetic. http://www.gradhermetic.es/.

(16) Warema. http://www.warema.es/.

(17) Keystone. http://keystonelintels.com/.

(18) Retrosolar. http://www.retrosolar.de/.

(19) Griesser Spain. http://www.griesser.es. 